\title{
Physicochemical and Catalytic Properties of Rhenium-Containing Zeolites in the Course of Straight-Run Gasoline Upgrading
}

\author{
Ludmila M. Velichkina*, \\ Yakov E. Barbashin and Alexander V. Vosmerikov \\ Institute of Petroleum Chemistry SB RAS \\ Tomsk, Russian Federation
}

Received 21.10.2020, received in revised form 25.07.2021, accepted 17.08.2021

\begin{abstract}
Catalysts for upgrading of the straight-run gasoline fraction of oil were prepared on the basis of a ZSM-5 zeolite via dry mechanical mixing with an ultrafine rhenium powder. It was shown how the structural and acidic characteristics of zeolite ZSM-5 changed when it was modified with rhenium. The concentration and nature of carbon condensation products formed on the prepared catalysts during the processing of straight-run gasoline have been determined. An enhancement of operating efficiency of rhenium-containing zeolite catalysts in comparison with an unmodified zeolite was established, which consisted in increasing their capacity and reducing the rate of deactivation in the process under study.
\end{abstract}

Keywords: ZSM-5 zeolite, ultrafine rhenium powder, modification, catalyst, surface, porosity, acid sites, straight-run gasoline fraction of oil, processing, coke, dynamics of deactivation.

(C) Siberian Federal University. All rights reserved

This work is licensed under a Creative Commons Attribution-NonCommercial 4.0 International License (CC BY-NC 4.0).

* Corresponding author E-mail address: mps@ipc.tsc.ru 


\title{
Физико-химические и каталитические свойства \\ ренийсодержащих цеолитов \\ в процессе облагораживания прямогонного бензина
}

\author{
Л. М. Величкина, Я. Е. Барбашин, А. В. Восмериков \\ Институт химии нефти СО РАН \\ Российская Федерация, Томск
}

\begin{abstract}
Аннотация. На основе цеолита структурного типа ZSM-5 сухим механическим смешением с ультрадисперсным порошком рения получены катализаторы для облагораживания прямогонной бензиновой фракции нефти. Показано изменение структурных и кислотных характеристик цеолита ZSM-5 при его модифицировании рением. Определена концентрация и природа углеродных продуктов уплотнения, образующихся на полученных катализаторах при переработке прямогонного бензина. Установлено повышение эффективности работы ренийсодержащих цеолитных катализаторов по сравнению с немодифицированным цеолитом, заключающееся в увеличении их производительности и снижении скорости дезактивации в исследованном процессе.
\end{abstract}

Ключевые слова: цеолит ZSM-5, ультрадисперсный порошок рения, модифицирование, катализатор, поверхность, пористость, кислотные центры, прямогонная бензиновая фракция нефти, переработка, кокс, динамика дезактивации.

Цитирование: Величкина, Л. М. Физико-химические и каталитические свойства ренийсодержащих цеолитов в процессе облагораживания прямогонного бензина / Л. М. Величкина, Я.Е. Барбашин, А. В. Восмериков // Журн. Сиб. федер. ун-та. Химия, 2021, 14(3). C. 371-380. DOI: 10.17516/1998-2836-0247

\section{Введение}

Цеоформинг, являющийся разновидностью каталитического риформинга, представляет интерес в качестве одного из процессов нефтеперерабатывающей промышленности при производстве автомобильных бензинов или их высокооктановых компонентов [1-6]. Эффективность процесса зависит от технологических режимов и от свойств используемого цеолитсодержащего катализатора, в том числе от продолжительности межрегенерационного периода его работы. Одной из основных причин, сдерживающих широкое промышленное применение процесса «Цеоформинг», остается относительно быстрая дезактивация катализатора, которая может быть устранена за счет увеличения продолжительности его стабильной работы при эксплуатации и улучшения способности катализатора к восстановлению активности путем его регенерации [7-9].

Одним из основных факторов, определяющих свойства катализатора, является его химический состав. В то же время и при сохранении химического состава каталитические свойства в зависимости от способа и условий приготовления могут изменяться в широких пределах вследствие изменения природы взаимодействия компонентов катализатора, дисперсности, 
пористой структуры, кристаллохимических изменений и других факторов, существенно влияющих на протекание каталитических реакций. Как показано нами в работах [10, 11], введение различными способами рения в цеолит ZSM-5 приводит к изменению качественных и количественных характеристик образующихся на нем высокооктановых бензинов, при этом бензин с наибольшим октановым числом образуется на цеолите, модифицированном ультрадисперсным порошком (УДП) рения. Кроме того, использование УДП рения в качестве модифицирующей добавки к цеолиту эффективно вследствие его высокой дисперсности и отсутствия вредных стоков при приготовлении катализатора.

Цель настоящей работы заключается в изучении физико-химических и каталитических свойств катализаторов, полученных на основе ZSM-5 с добавкой различного количества УДП рения, в процессе облагораживания прямогонной бензиновой фракции нефти.

\section{Материалы и методы}

\section{Приготовление катализаторов}

Цеолит ZSM-5 с силикатным модулем 40 был получен методом гидротермального синтеза с использованием гексаметилендиамина в качестве структурообразующей добавки. Модифицирование цеолита в Н-форме проводили методом сухого смешения с УдП рения, полученного электровзрывным способом, в вибромельнице КМ-1 на воздухе в течение 2 ч. Содержание рения в катализаторах составляло 0,5 и 2,0 мас.\%, средний размер частиц УДП рения 770 нм. Для предотвращения окисления рения, добавленного к цеолиту, модифицированные образцы не прокаливали. Полученные порошкообразные смеси образцов прессовали в таблетки, измельчали и отбирали для испытаний фракцию 0,5-1,0 мм.

\section{Исследование структурных характеристик катализаторов}

Удельную поверхность катализаторов $(S)$ определяли методом Брунауэра-ЭмметаТеллера (BET) из данных низкотемпературной (минус $196^{\circ} \mathrm{C}$ ) адсорбции азота, полученных с использованием автоматического газоадсорбционного анализатора Sorbtometer M (ЗАО «КАТАКОН», Россия). Для очистки поверхности образцов перед началом измерений проводили их «тренировку», заключающуюся в прогреве при $260{ }^{\circ} \mathrm{C}$ в течение 100 мин в стационарном потоке смеси гелия и азота заданного состава. Десорбцию азота осуществляли при $40{ }^{\circ} \mathrm{C}$. Объем и размер пор образцов вычисляли с помощью модели ВЈH (BarettJoyner-Halenda) из данных изотерм адсорбции и десорбции при относительном давлении $P / P_{0}=0,99$.

\section{Исследование кислотных свойств ичеолитных катализаторов}

Кислотные свойства катализаторов изучали методом температурно-программированной десорбции (ТПД) аммиака, позволяющим определить распределение кислотных центров по силе и их количество. Хроматографический вариант программированной термодесорбции заключается в том, что образец с предварительно адсорбированными на нем молекулами вещества-зонда (аммиак) подвергается нагреванию со скоростью $10{ }^{\circ} \mathrm{C} /$ мин в токе гелия. Концентрация кислотных центров соответствует количеству десорбированного аммиака, а их сила - температурным максимумам на десорбционной кривой.

$$
-373-
$$




\section{Исследование каталитической активности иеолитов}

Каталитическую активность и стабильность исходного цеолита и ренийсодержащих цеолитных катализаторов исследовали в установке проточного типа с неподвижным слоем катализатора в процессе облагораживания прямогонной бензиновой фракции (НК-155 $\left.{ }^{\circ} \mathrm{C}\right)$ нефти следующего состава (мас.\%): 25,7 н-алканы $\mathrm{C}_{3}$ - $\mathrm{C}_{14}, 29,4$ изоалканы $\mathrm{C}_{4}-\mathrm{C}_{10}, 8,0$ арены $\mathrm{C}_{6}-\mathrm{C}_{12}, 36,9$ циклоалканы $\mathrm{C}_{5}-\mathrm{C}_{11}$. Октановое число прямогонного бензина по исследовательскому методу составляло 68 пунктов. Объем загружаемого в реактор катализатора равнялся $4 \mathrm{~cm}^{3}$, а размер его гранул - 0,5-1,0 мм. Динамику дезактивации цеолитных систем исследовали в течение 30 ч непрерывной работы при атмосферном давлении, температуре $380{ }^{\circ} \mathrm{C}$ и объемной скорости подачи исходного сырья 2 ч$^{-1}$. Отбор проб образующихся продуктов реакции проводили через 1,15 и 30 ч работы катализаторов. В качестве показателя каталитической активности образцов было принято содержание ароматических углеводородов в получаемых бензинах, а их эффективность работы, выраженная в октанотоннах, оценивалась по производительности, рассчитанной как произведение выхода катализата на его октановое число.

\section{Определение состава исходной бензиновой фракции}

и продуктов ее переработки

Анализ состава исходного сырья и продуктов его превращения осуществляли методом газожидкостной хроматографии с использованием хроматографа «Хроматэк-Кристалл 5000.2» (ГК «Новые технологии», Россия). Для определения состава жидкой фазы использовали капиллярную колонку BP-1 PONA (100 м × 0,25 мм × 0,5 мкм), а газовой фазы - капиллярную GS-Gas-Pro (60 м × 0,32 мм) и набивную Carbosieve S-II (4 м × 2 мм) колонки. Октановые числа исходного сырья и полученных катализатов определяли расчетным методом на основе хроматографических данных.

\section{Исследование коксовых отложений на катализаторах}

Изучение природы коксовых отложений, образующихся на поверхности исследуемых катализаторов в процессе превращения прямогонной бензиновой фракции нефти, проводили методом дифференциально-термического анализа с помощью дериватографа Q-1500 D системы Паулик-Паулик-Эрдей (МОМ, Венгрия). Для обработки результатов измерений использовали программный продукт Tanaliz, обеспечивающий контроль и измерение температуры $(T)$ и скорости $(W)$ нагрева образца, изменения массы образца (ТГ), тепловых эффектов (ДТА). Скорость нагрева исследуемого образца составляла $10{ }^{\circ} \mathrm{C} / \mathrm{мин,} \mathrm{а} \mathrm{его} \mathrm{масса}-400$ мг, измерения проводились в атмосфере воздуха. В качестве образца сравнения использовали оксид алюминия $\left(\alpha-\mathrm{Al}_{2} \mathrm{O}_{3}\right)$.

\section{Обсуждение результатов}

\section{Структурные характеристики цеолитов}

В табл. 1 показаны структурные характеристики исходного цеолита ZSM-5 и его модифицированных форм. Наибольшую суммарную удельную поверхность и объем пор имеет исходный цеолит, однако распределение мезо- и макропор зависит от концентрации добавленного к цеолиту рения. Так, удельная поверхность микропор цеолита снижается при его модифици- 
Таблица 1. Структурные характеристики цеолитных катализаторов

Table 1. Structural characteristics of zeolite catalysts

\begin{tabular}{|c|c|c|c|c|c|c|c|}
\hline Образец & $S_{\text {ВЕт }}, \mathrm{M}^{2} / \Gamma$ & $\begin{array}{c}S_{\text {мезо }} \\
\mathrm{M}^{2} / \Gamma\end{array}$ & $\begin{array}{c}S_{\text {микро }} \\
\mathrm{M}^{2} / \Gamma\end{array}$ & $V_{\text {общ }}, \mathrm{cm}^{3} / \Gamma$ & $\begin{array}{c}V_{\text {мезо }} \\
\mathrm{cm}^{3} / \Gamma\end{array}$ & $\begin{array}{c}V_{\text {микро, }} \\
\mathrm{cm}^{3} / \Gamma\end{array}$ & $\begin{array}{c}D, \\
\text { нм }\end{array}$ \\
\hline ZSM-5 & 443 & 158 & 285 & 0,19 & 0,06 & 0,13 & 2,00 \\
\hline $0,5 \% \operatorname{Re} / Z S M-5$ & 416 & 137 & 279 & 0,17 & 0,10 & 0,07 & 1,68 \\
\hline $2,0 \% \operatorname{Re} / Z S M-5$ & 339 & 202 & 137 & 0,17 & 0,10 & 0,07 & 1,94 \\
\hline
\end{tabular}

Примечание. $S_{\mathrm{BET}}$ - удельная поверхность катализатора, измеренная по методу ВЕТ; $S_{\text {мезо }}, S_{\text {микро }}-$ удельная поверхность мезо- и микропор; $V_{\text {общ }}$ - общий удельный объем пор; $V_{\text {мезо }}, V_{\text {микро }}$-удельный объем мезо- и микропор; $D$ - средний диаметр пор.

ровании, в то время как удельная поверхность мезопор для образца 2,0 \%Re/ZSM-5, напротив, возрастает. Добавка УДП рения к цеолиту также способствует увеличению объема его мезопор. Уменьшение среднего диаметра пор с 2,00 до 1,68 нм происходит при добавлении 0,5 \% рения, однако увеличение концентрации рения в цеолите до 2,0 \% приводит к восстановлению практически прежнего диаметра пор. Наблюдаемые изменения структурных характеристик связаны преимущественно с расположением частиц рения на поверхности цеолита с образованием больших полостей с одновременной частичной блокировкой его микропор.

\section{Кислотные свойства цеолитных катализаторов}

В табл. 2 приведены кислотные свойства исходного цеолита и ренийсодержащих цеолитных катализаторов. Все образцы имеют два типа кислотных центров: низкотемпературные с областью десорбции аммиака от 100 до $300{ }^{\circ} \mathrm{C}$, представленные координационно-ненасыщенными ионами алюминия, и высокотемпературные, в качестве которых могут выступать ионы водорода мостиковых гидроксильных групп, с которых аммиак удаляется в интервале температур - от 300 до $600{ }^{\circ} \mathrm{C}$. Температурные максимумы пиков, свидетельствующие о силе кислотных центров цеолита, указывают на ее снижение в случае добавления к нему $0,5 \% \operatorname{Re}$ и на увеличение при добавлении $2,0 \% \operatorname{Re}$. Концентрация кислотных центров, рассчитанная по площади пиков под термодесорбционными кривыми, снижается при добавлении УдП рения независимо от его концентрации в результате экранирования кислотных центров цеолита

Таблица 2. Кислотные характеристики исходного цеолита и ренийсодержащих цеолитных катализаторов Table 2. Acidic characteristics of the initial zeolite and rhenium-containing zeolite catalysts

\begin{tabular}{|c|c|c|c|c|c|}
\hline \multirow{2}{*}{ Катализатор } & \multicolumn{2}{|c|}{$T_{\text {макс. }}$ формы, ${ }^{\circ} \mathrm{C}$} & \multicolumn{3}{c|}{ Концентрация кислотных центров, } \\
& $\mathrm{T}_{\mathrm{I}}$ & $\mathrm{T}_{\mathrm{II}}$ & $\mathrm{C}_{\mathrm{I}}$ & $\mathrm{C}_{\mathrm{II}}$ & $\mathrm{C}_{\Sigma}$ \\
\cline { 2 - 6 } & 210 & 425 & 532 & 266 & 798 \\
\hline ZSM-5 & 205 & 420 & 492 & 263 & 755 \\
\hline $0,5 \% \operatorname{Re} / \mathrm{ZSM}-5$ & 220 & 430 & 489 & 234 & 723 \\
\hline $2,0 \% \operatorname{Re} / Z \mathrm{ZSM}-5$ & &
\end{tabular}

Примечание. $T_{I}, T_{I I}$ - температуры максимумов низко- и высокотемпературных пиков на термодесорбционных кривых; $C_{I}, C_{I I}$ и $C_{\Sigma}$ - концентрации слабых и сильных кислотных центров и их сумма соответственно. 
частицами рения. Металлсодержащие центры, формирующиеся в результате промотирования цеолита рением, способны активировать молекулы исходных алканов и промежуточных алкенов, ускоряя процесс их дегидрирования. На сильных кислотных центрах цеолита протекает преимущественно процесс крекинга и скелетная перегруппировка активированных молекул. Исходя из полученных данных по кислотным свойствам образцов, можно предположить, что катализатор 2,0 \%Re/ZSM-5, отличающийся более высокой силой кислотных центров обоих типов, проявит бо́льшую ароматизирующую активность в процессе превращения прямогонной бензиновой фракции нефти, но при этом, вероятно, будет наблюдаться снижение выхода катализата в результате увеличения скорости протекания реакций крекинга.

\section{Каталитические свойства исходного}

и ренийсодержащих цеолитов

В табл. 3 представлен состав газообразных продуктов, образующихся на цеолитных катализаторах при облагораживании прямогонного бензина. Для всех образцов в ходе протекания процесса в течение 30 ч характерно небольшое увеличение выхода низших алканов с одновременным снижением доли изоалканов и алкенов, что свидетельствует о некотором снижении активности катализаторов в результате образования на их поверхности углеродных продуктов уплотнения. Состав газообразных продуктов реакции, полученных на ренийсодержащих образцах, по сравнению с немодифицированным цеолитом отличается незначительно.

В табл. 4 показано влияние продолжительности процесса превращения прямогонной бензиновой фракции нефти на исследуемых катализаторах на выход и состав образующихся жидких продуктов и на производительность катализаторов. На ренийсодержащих образцах, по сравнению с исходным цеолитом, повышается выход таких высокооктановых компонентов, как изоалканы и ароматические углеводороды, что приводит к увеличению октановых чисел катализатов, с одновременным снижением концентрации циклоалканов. В результате повышенной каталитической активности образцов, содержащих рений, снижается образование на них жидких продуктов реакции.

Таблица 3. Состав газообразных продуктов превращения прямогонной бензиновой фракции нефти на цеолитных катализаторах $\left(\mathrm{T}=380{ }^{\circ} \mathrm{C}\right)$

Table 3. Composition of gaseous products of conversion of straight-run gasoline fraction of oil over zeolite catalysts $\left(\mathrm{T}=380^{\circ} \mathrm{C}\right)$

\begin{tabular}{|c|c|c|c|c|}
\hline \multirow{2}{*}{ Катализатор } & \multirow{2}{*}{ Продукты,\% } & \multicolumn{3}{|c|}{ Длительность процесса, ч } \\
\cline { 3 - 5 } & & 1 & 15 & 30 \\
\hline \multirow{3}{*}{ ZSM-5 } & Н-алканы $\mathrm{C}_{1}-\mathrm{C}_{5}$ & 71,4 & 73,9 & 75,1 \\
& Изоалканы $\mathrm{C}_{4}-\mathrm{C}_{5}$ & 25,9 & 24,2 & 23,3 \\
& Алкены $\mathrm{C}_{2}-\mathrm{C}_{4}$ & 2,7 & 1,9 & 1,6 \\
\hline \multirow{3}{*}{$0,5 \% \operatorname{Re} / Z \mathrm{ZSM}-5$} & Н-алканы $\mathrm{C}_{1}-\mathrm{C}_{5}$ & 70,4 & 73,8 & 75,5 \\
& Изоалканы $\mathrm{C}_{4}-\mathrm{C}_{5}$ & 27,2 & 24,7 & 23,2 \\
& Алкены $\mathrm{C}_{2}-\mathrm{C}_{4}$ & 2,4 & 1,5 & 1,3 \\
\hline \multirow{3}{*}{$2,0 \% \operatorname{Re} / Z \mathrm{ZSM}-5$} & Н-алканы $\mathrm{C}_{1}-\mathrm{C}_{5}$ & 70,0 & 72,5 & 75,0 \\
& Изоалканы $\mathrm{C}_{4}-\mathrm{C}_{5}$ & 27,7 & 25,8 & 23,5 \\
& Алкены $\mathrm{C}_{2}-\mathrm{C}_{4}$ & 2,3 & 1,7 & 1,5 \\
\hline
\end{tabular}


Таблица 4. Зависимость выхода, состава и октанового числа катализатов, полученных в процессе превращения прямогонной бензиновой фракции нефти, от длительности работы цеолитных катализаторов и их производительность $\left(\mathrm{T}=380{ }^{\circ} \mathrm{C}\right)$

Table 4. Yield, composition, and octane number of catalysts obtained in the course of conversion of the straightrun gasoline fraction of oil $v s$ the life time of zeolite catalysts and their productivity $\left(\mathrm{T}=380{ }^{\circ} \mathrm{C}\right)$

\begin{tabular}{|c|c|c|c|c|}
\hline \multirow{2}{*}{ Катализатор } & \multirow{2}{*}{ Продукты } & \multicolumn{3}{|c|}{ Длительность процесса, ч } \\
\hline & & 1 & 15 & 30 \\
\hline \multirow[t]{4}{*}{ ZSM-5 } & $\begin{array}{l}\text { Н-алканы } \mathrm{C}_{3}-\mathrm{C}_{12} \\
\text { Изоалканы } \mathrm{C}_{4}-\mathrm{C}_{10} \\
\text { Арены } \mathrm{C}_{6}-\mathrm{C}_{12} \\
\text { Циклоалканы } \mathrm{C}_{5}-\mathrm{C}_{10} \\
\text { Алкены } \mathrm{C}_{4}-\mathrm{C}_{10}\end{array}$ & $\begin{array}{c}6,4 \\
33,0 \\
28,0 \\
28,6 \\
4,0\end{array}$ & $\begin{array}{c}29,1 \\
28,5 \\
13,1 \\
26,5 \\
2,8\end{array}$ & $\begin{array}{c}33,5 \\
28,1 \\
10,6 \\
25,7 \\
2,1\end{array}$ \\
\hline & Октановое число & 92 & 76 & 72 \\
\hline & Выход,\% & 69 & 86 & 92 \\
\hline & Производительность, октано-тонна & 6348 & 6536 & 6624 \\
\hline \multirow[t]{4}{*}{$0,5 \% \operatorname{Re} / Z S M-5$} & $\begin{array}{l}\mathrm{H} \text {-алканы } \mathrm{C}_{3}-\mathrm{C}_{12} \\
\text { Изоалканы } \mathrm{C}_{4}-\mathrm{C}_{10} \\
\text { Арены } \mathrm{C}_{6}-\mathrm{C}_{12} \\
\text { Циклоалканы } \mathrm{C}_{5}-\mathrm{C}_{10} \\
\text { Алкены } \mathrm{C}_{4}-\mathrm{C}_{10}\end{array}$ & $\begin{array}{l}10,1 \\
35,0 \\
34,0 \\
18,1 \\
2,8\end{array}$ & $\begin{array}{c}28,5 \\
29,1 \\
22,1 \\
18,0 \\
2,3\end{array}$ & $\begin{array}{l}31,9 \\
28,9 \\
19,0 \\
17,9 \\
2,3\end{array}$ \\
\hline & Октановое число & 94 & 82 & 80 \\
\hline & Выход,\% & 65 & 79 & 84 \\
\hline & Производительность, октано-тонна & 6110 & 6478 & 6720 \\
\hline \multirow[t]{4}{*}{$2,0 \% \operatorname{Re} / \mathrm{ZSM}-5$} & $\begin{array}{l}\text { Н-алканы } \mathrm{C}_{3}-\mathrm{C}_{12} \\
\text { Изоалканы } \mathrm{C}_{4}-\mathrm{C}_{10} \\
\text { Арены } \mathrm{C}_{6}-\mathrm{C}_{12} \\
\text { Циклоалканы } \mathrm{C}_{5}-\mathrm{C}_{10} \\
\text { Алкены } \mathrm{C}_{4}-\mathrm{C}_{10}\end{array}$ & $\begin{array}{c}13,8 \\
26,1 \\
35,8 \\
22,1 \\
2,2\end{array}$ & $\begin{array}{c}18,0 \\
31,1 \\
25,1 \\
23,5 \\
2,3\end{array}$ & $\begin{array}{c}17,6 \\
32,4 \\
22,4 \\
25,6 \\
2,0\end{array}$ \\
\hline & Октановое число & 95 & 85 & 83 \\
\hline & Выход,\% & 63 & 76 & 80 \\
\hline & Производительность, октанотонна & 5985 & 6460 & 6640 \\
\hline
\end{tabular}

Производительность всех катализаторов повышается при увеличении времени их работы. При этом наибольшую производительность в течение первых 15 ч процесса переработки прямогонного бензина проявляет исходный ZSM-5. После 30 ч работы производительность ренийсодержащих катализаторов становится выше по сравнению с немодифицированным образцом. Зависимость производительности катализатора не линейна от содержания в нем УДП рения, так, после 30 ч процесса производительность уменьшается в ряду: 0,5 \%Re/ZSM-5>2,0 \%Re/ZSM-5> ZSM-5.

Еще одним важным оценочным фактором эффективности работы катализатора является его устойчивость к закоксовыванию или скорость снижения активности со временем работы катализатора, за меру которой выбрана концентрация ароматических углеводородов в полученных бензинах. По этому показателю исследованные катализаторы за 30 ч работы снизили свою активность в 2,6 (ZSM-5), 1,8 (0,5 \%Re/ZSM-5) и 1,6 раза (2,0\%Re/ZSM-5).

Таким образом, введение в цеолит УДП рения повышает производительность и способствует более длительной стабильной работе катализатора в процессе облагораживания прямогонного бензина. 


\section{Характеристика углеродных отложений на катализаторах}

От количества и степени конденсированности углеродных отложений, образующихся на катализаторе в ходе реакции, зависят условия его регенерации и количество циклов, которые образец может выдержать без существенного изменения своих свойств.

На рис. 1 приведены результаты дифференциально-термического анализа исходного ZSM-5 (рис. 1, $a$ ) и ренийсодержащих цеолитных катализаторов, проработавших в процессе облагораживания прямогонного бензина при $380^{\circ} \mathrm{C}$ в течение 30 ч (рис. 1,б, в). Кривые ДТА образцов ZSM-5 (рис. 1,a) и 0,5 \%Re/ZSM-5 (рис. 1,б) имеют схожий вид, в то время как кривая ДТА катализатора 2,0 \%Re/ZSM-5 (рис. 1,в) отличается от них наличием четко выраженного «плеча» в области $200-500{ }^{\circ} \mathrm{C}$. Температурный максимум на кривой ДТА для исходного образца соответствует температуре $566^{\circ} \mathrm{C}$ (рис. 1,a). Введение УДП рения в цеолит в обоих случаях приводит к смещению максимума в низкотемпературную область на 12 градусов Цельсия. Кривые ДТГ исходного ZSM-5 (рис. 1,a) и образца, содержащего 2,0 мас.\% рения (рис. 1,6), напротив, в области десорбции адсорбированной и слабосвязанной воды характеризуются наличием двух четко выраженных максимумов, в то время как кривая ДТГ образца 0,5 \%Re/ZSM-5 (рис. 1,б) в этой области имеет один максимум при $192{ }^{\circ} \mathrm{C}$.
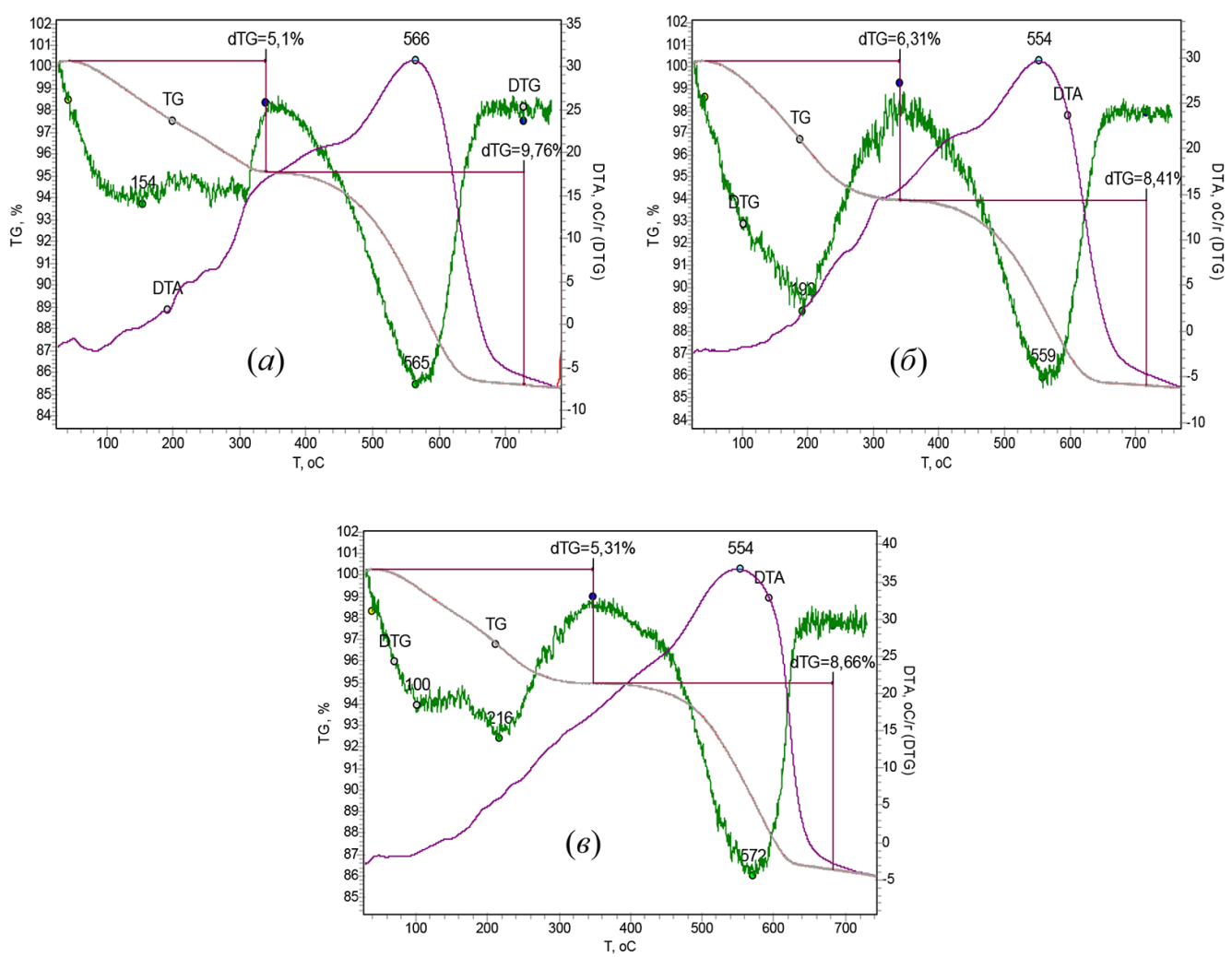

Рис. 1. Данные термического анализа катализаторов ZSM-5 (a), 0,5 \%Re/ZSM-5 (б), 2,0 \%Re/ZSM-5 (в), проработавших в процессе превращения прямогонной бензиновой фракции нефти в течение 30 ч

Fig. 1. Thermal analysis data for the catalysts ZSM-5 (a), 0,5\% Re/ZSM-5 (b), and 2,0\% Re/ZSM-5 (c), which worked for $30 \mathrm{~h}$ during the conversion of straight-run gasoline fraction of oil 
На дериватограммах также указано изменение массы по отношению к массе навески закоксованного катализатора. Для количественного сопоставления результатов использовали величину, отнесенную к массе «чистого» после выжигания кокса катализатора. Минимальное количество воды имелось в исходном образце ZSM-5 (5,10 \%), немного больше воды содержал катализатор 2,0 \%Re/ZSM-5 (5,31 \%), в образце 0,5 \%Re/ZSM-5 содержание воды было наибольшим $-6,31 \%$.

Широкие четко выраженные «плечи» и максимумы на кривых ДТА исследуемых образцов указывают на неоднородность образовавшегося кокса и присутствие нескольких его форм. Наблюдаемые выше $340{ }^{\circ} \mathrm{C}$ экзотермические эффекты и пики на кривых ДТГ соответствуют удалению коксовых отложений. Температура конца выгорания углеродных продуктов для исследуемых катализаторов несколько отличается и составляет 666, 660 и $640{ }^{\circ} \mathrm{C}$ соответственно для образцов ZSM-5, 0,5 \%Re/ZSM-5 и 2,0 \%Re/ZSM-5. Коксовые отложения, содержащиеся на катализаторе 2,0 \%Re/ZSM-5, удаляются при более низкой температуре и в более узком температурном интервале по сравнению с двумя другими образцами.

По данным дифференциально-термического анализа, общая масса коксовых отложений на исходном цеолите ZSM-5 после 30 ч его работы в процессе превращения прямогонной бензиновой фракции нефти составляет 9,76 \%. Это самое высокое содержание кокса, на катализаторах 0,5\%Re/ZSM-5 и 2,0 \% Re/ZSM-5 его содержится соответственно 8,41 и $8,66 \%$.

Таким образом, на цеолитах, содержащих УДП рения, образуется меньшее количество продуктов уплотнения, которые характеризуются менее конденсированной структурой по сравнению с исходным цеолитом, что связано как с более интенсивным протеканием на них реакций гидрирования конденсированных молекул - предшественников коксовых образований, так и с наличием бо́льшего количества мезопор.

\section{Заключение}

Модифицирование цеолита ZSM-5 рением повышает эффективность его работы при облагораживании прямогонной бензиновой фракции нефти, что выражается в снижении скорости его дезактивации и повышении производительности в ходе длительной эксплуатации.

\section{Благодарности / Acknowledgements}

Работа выполнена в рамках государственного задания ИХН СО РАН (проект V.46.2.1), финансируемого Министерством науки и высшего образования Российской Федерации.

The work was carried out within the framework of the Project V.46.2.1, funded by the Ministry of Science and Higher Education of the Russian Federation.

\section{Список литературы / References}

1. Degnan T.F., Chitnis G. K., Schipper P.H. History of ZSM-5 fluid catalytic cracking additive development at Mobil. Microporous and Mesoporous Materials 2000. Vol. 35-36, P. 245-252.

2. Degnan Jr. T.F. Applications of zeolites in petroleum refining. Topics in Catalysis 2000. Vol. 13(4), P. 349-356.

$$
-379-
$$


3. den Hollander M. A., Wissink M., Makkee M., Moulijn J.A. Gasoline conversion: reactivity towards cracking with equilibrated FCC and ZSM-5 catalysts. Applied Catalysis A: General 2001. Vol. 223(1-2), P. 85-102.

4. Aboul-Gheit A.K., Aboul-Gheit N.A.K., Aboul-Fotouh S. M. Hydroconversion of cyclohexene using catalysts containing Pt, Pd, Ir and Re supported on H-ZSM-5 zeolite. Applied Catalysis A: General 2005. Vol. 283(1-2), P. 157-161.

5. Мамедов С.Э., Ахмедова Н.Ф., Мирзалиева С. Э., Мирзаи Д. И., Ахмедов Э. И., Азмамедова Х.М., Дадашева С.С. Превращение н-гексана и прямогонной бензиновой фракции на модифицированных пентасилах. НефтеГазоХимия 2018 (1), С. 35-38. [Mamedov S. E., Akhmedova N.F., Mirzaliyeva S. E., Mirzai D. I., Akhmedov E. I., Azmamedova Kh.M., Dadasheva S. S. Transformation of n-hexane and straigt-run gasoline on to modified pentasyles. Oil\&GasChemistry 2018 (1), P. 35-38. (In Russ.)]

6. Алтынов А. А., Богданов И. А., Темирболат А. М., Белинская Н. С., Киргина М.В. Исследование влияния состава сырья и технологических параметров на характеристики продуктов цеоформинга стабильного газового конденсата. Нефтепереработка и нефтехимия 2019 (11), C. 9-14. [Altynov A. A., Bogdanov I. A., Temirbolat A. M., Belinskaya N. S., Kirgina M. V. Study of the effect of raw materials composition and technological parameters on the characteristics of the producrs of zeoforming of stable gas condensate. Oil Refining and Petrochemistry 2019 (11), P. 9-14. (In Russ.)]

7. Rautiainen E., Pimenta R., Ludvig M., Pouwels C. Deactivation of ZSM-5 additives in laboratory for realistic testing. Catalysis Today 2009. Vol. 140(3-4), P. 179-186.

8. Echevsky G.V., Kodenev E.G., Nosyreva G.N. Methods of increasing the stability of the catalytic effect of MFI type zeolites and the total service life of catalysts based on them. Catalysis in Industry 2013. Vol. 5(4), P. 275-282.

9. Зеленская Е.А., Зеленская Т.В., Ладенко А.А. Особенности коксообразования на органически модифицированных цеолитных катализаторах нефтепереработки. Экспозиция Нефть Газ 2018 (5), C. 69-71. [Zelenskaya E. A., Zelenskaya T. V., Ladenko A. A. Features of coke formation on organically modified zeolite catalysts of oil refining. Exposition Oil\&Gas 2018 (5), P. 69-71. (In Russ.)]

10. Величкина Л.М., Восмериков А.В. Облагораживание прямогонной бензиновой фракции нефти на ренийсодержащих цеолитах типа ZSM-5. Нефтепереработка и нефтехимия 2017 (5), C. 7-13. [Velichkina L. M., Vosmerikov A. V. Upgrading of once-run petrol of oil on rheniumcontaing zeolites of ZSM-5 type. Oil Refining and Petrochemistry 2017 (5), P. 7-13. (In Russ.)]

11. Величкина Л.М., Барбашин Я.Е., Восмериков А.В. Влияние рения на физикохимические свойства цеолита типа MFI и динамику его дезактивации в процессе облагораживания прямогонной бензиновой фракции нефти. Химия в интересах устойчивого развития 2020. T. 28(3), C. 229-235. [Velichkina L. M., Barbashin Ya.E., Vosmerikov A. V. Effect of Rhenium on the Physicochemical Properties of MFI-type Zeolite and the Dynamics of its Deactivation in the Course of Upgrading the Straight-Run Gasoline Fraction of Oil. Chemistry for Sustainable Development 2020. Vol. 28(3), P. 229-235. (In Russ.)] 